\title{
EL SISTEMA LANKESTER
}

\author{
ROBERT L. DRESSLER \\ Jardín Botánico Lankester, Universidad de Costa Rica \\ P.O. Box 1031-7050 Cartago, Costa Rica, CA•rdressle@cariari.ucr.ac.cr
}

En muchas de las charlas, el ponente presenta su charla en inglés para favorecer a los visitantes extranjeros. En este caso, creo que el material que quiero presentar es de más interés para los visitantes de América Tropical que para los de habla inglesa. En mi experiencia, todos los jardines botánicos, tal vez con excepción de Longwood, hallan que no tienen los recursos suficientes para para hacer lo que deben hacer. En la realidad, la mayoría de los jardines botánicos en los Estados Unidos y Europa tienen más apoyo y más recursos que la mayoría de los jardines botánicos en los trópicos. Para que un jardín sea un jardín botánico, creo que el elemento más crítico es un sistema de datos. En el Jardín Botánico Lankester (JBL) ya tenemos un sistema que funciona con poca plata, y creo que les puede ser de interés. Normalmente, lo llamamos "el sistema Lankester," pero igualmente lo podríamos llamar el sistema Pupulin.

En muchos de los jardines botánicos de zonas templadas, hay una oficina de "adquisición." Todas las plantas que entran al jardín tienen que recibir un número en esta oficina, lo cual implica al menos una persona a tiempo completo. En nuestro caso, tenemos pocas personas a tiempo completo, pero sí tenemos una serie de estudiantes que trabajan unas horas cada semana. Tenemos la intención de dar un número, más bien de "acceso" que de adquisición, a cada planta que se cultiva en nuestros invernaderos. Para que este sistema funcione, usamos también números de colecta de cada estudiante y empleado que colecte plantas, para que haya un sistema que asocie cada planta con sus datos de origen, hasta que la planta tenga su número de acceso del jardín.

En el caso de material conservado, el material prensado en el campo recibe su número de colecta del colector, aún cuando una parte de la misma planta puede ser cultivada en el invernadero (con el mismo número). Por ahora, no mantenemos una colección permanente de material prensado, pues bajo nuestras condiciones de humedad, ninguna colección de material prensado puede ser permanente. Normalmente depositamos material en el Herbario de la Universidad de Costa Rica (USJ) o en el Museo Nacional (CR). La humedad no interfiere con una colección de material en alcohol, y en el JBL mantenemos una colección muy útil de material en alcohol. A mi modo de ver, lo ideal sería agrupar el material en un orden sistemático o filogenetico, pero en la práctica usamos un sistema por tamaño de frasco pequeño, mediano, grande o largo, y hay una base de datos, por lo cual uno puede accesar por género o especie.

Ahora usamos unas etiquetas en las cuales uno puede marcar si hemos prensado material, si hay material en líquido, o si hay material para ADN (en silica), si hay foto o dibujo de la planta.

Franco ha inventado un sistema en que se escanea la planta, la flor, o partes de la flor, y uno puede hacer un buen dibujo de estos escaneos. Por cierto, hay que tener cuidado de no perder a algunos detalles superficiales, que pueden desaparecer o disminuir cuando se aplastan las partes florales.

Robert L. Dressler obtuvo su doctorado en la Universidad de Harvard y laboró con el Jardín Botánico de Missouri y el Instituto Smithsoniano para la Investigación Tropical. Es investigador asociado al Herbario de la Universidad de Florida, el Jardín Botánico de Missouri y el Jardín Botánico Mary Selby. Es autor de centenares de artículos científicos y de reconocidos libros sobre historia natural, filogenia y clasificación de las orquídeas. Su principal interés se centra en la fiologenia y taxonomía de la subtribu Sobralinae. Actualmente labora para el Jardín Botánico Lankester de la Universidad de Costa Rica donde se desempeña como Coordinador de Investigación. 